\title{
Toprak neminin yarı kurak alanlarda çok zamanlı RADARSAT-2 verileri ile incelenmesi
}

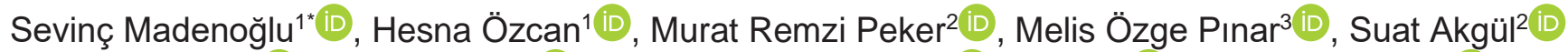

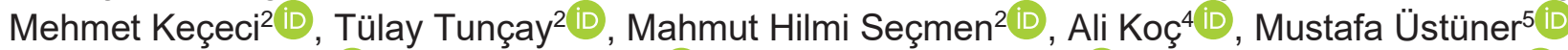

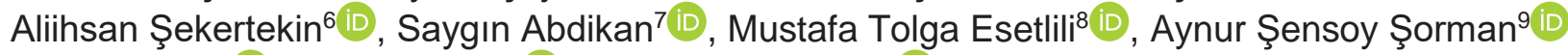 \\ Şinasi Kaya ${ }^{10}$ iD, Günay Erpul11 (iD), Füsun Balık Şanlı ${ }^{12}$ (D) \\ ${ }^{1}$ T.C. Tarım ve Orman Bakanlığı, Tarımsal Araştırmalar ve Politikalar Genel Müdürlüğü, Ankara, Türkiye. \\ ${ }^{2}$ T.C. Tarım ve Orman Bakanlığı, Tarımsal Araştırmalar ve Politikalar Genel Müdürlüğü, Toprak Gübre ve Su Kaynakları Merkez Araştırma Enstitüsü Müdürlüğü, \\ Ankara, Türkiye. \\ ${ }^{3}$ T.C. Tarım ve Orman Bakanlığı, Tarımsal Araştırmalar ve Politikalar Genel Müdürlüğü, Geçit Kuşağı Tarımsal Araştırma Enstitüsü Müdürlüğü, Eskişehir, Türkiye. \\ ${ }^{4}$ T.C. Tarım ve Orman Bakanlığı, Tarım Işletmeleri Genel Müdürlüğü, Ankara, Türkiye. \\ ${ }^{5}$ Artvin Çoruh Üniversitesi, Mühendislik Fakültesi, Harita Mühendisliği Bölümü, Artvin, Türkiye. \\ ${ }^{6}$ Çukurova Üniversitesi, Ceyhan Mühendislik Fakültesi, Harita Mühendisliği Bölümü, Ceyhan, Adana, Türkiye. \\ ${ }^{7}$ Hacettepe Üniversitesi, Beytepe Kampüsü, Mühendislik Fakültesi, Geomatik Mühendisliği Bölümü, Çankaya, Ankara, Türkiye. \\ ${ }^{8}$ Ege Üniversitesi, Ziraat Fakültesi, Toprak Bilimi ve Bitki Besleme Bölümü, Bornova, Izmir, Türkiye. \\ ${ }^{9}$ Eskişehir Teknik Üniversitesi, Mühendislik Fakültesi, Inşaat Mühendisliği Bölümü, Eskişehir, Türkiye. \\ ${ }^{10}$ Istanbul Teknik Üniversitesi, Ayazağa Kampüsü, Inşaat Fakültesi, Geomatik Mühendisliği Bölümü, Sarıyer, İstanbul, Türkiye. \\ ${ }^{11}$ Ankara Üniversitesi, Ziraat Fakültesi, Toprak Bilimi ve Bitki Besleme Bölümü, Altındağ, Ankara, Türkiye. \\ ${ }^{12}$ Yıldız Teknik Üniversitesi, Davutpaşa Kampüsü, Inşaat Fakültesi, Harita Mühendisliği Bölümü, Esenler, İstanbul, Türkiye.
}

Öz: Toprak nemi içeriği yeryüzünde enerji değişimi ve su döngüsü açısından çok önemli bir faktördür ve doğal risklerin değerlendirilmesi, hidroloji, ekoloji, tarım ve iklim bilimi gibi pek çok alanda büyük etkiye sahiptir. Toprak nemi özellikle arazi kullanımlarında konumsal ve zamansal olarak çok fazla değişerek çeşitli çevresel ve ekolojik sorunlara yol açabilmektedir. Bu nedenlerden dolayl, toprak nem içeriğinin konumsal değişiminin geniş ölçeklerde incelenmesi önemli bir araştırma konusudur. Sentetik Açıklıklı Radar (SAR) algılayıcıları toprak nemine duyarlı olduklarl ve geniş alanları kapsadıkları için toprak neminin tespit edilmesinde önemli rol oynamaktadır. Bu çalışmada, Tarım İşletmeleri Genel Müdürlüğ̈̈ Gözlü Tarım Işsletmesi'nde seçilen buğday ekili ve nadasa bırakılmış tarlaların toprak nem içeriğinin konumsal ve zamansal değișiminin tam polarimetrik RADARSAT-2 görüntüleri ile belirlenebilirliğinin araștırılması amaçlanmıştır. 2016 yılı Mart ve Ekim ayları arasında yapılan aylık arazi ölçümlerinden elde edilen yersel ölçüm değerleri SAR gerisaçılım değerleri ile karşılaştırılmıştır. Çalışma sonucunda, doğrudan geri saçılım ile nem değerleri arasında -0.65 ile 0.67 arasında değișen negatif ve pozitif korelasyon katsayıları elde edilmiştir. Toprak nemi için ekili alanda buğdayın büyüme evresi olan Mayı-Haziran döneminde daha yüksek korelasyon belirlenmiş olup, her iki alan için en iyi sonuç VV polarimetrik verisi ile elde edilmiştir.

Anahtar Sözcükler: Toprak nemi, Zamansal analiz, SAR, RADARSAT-2

\section{Analysis of soil moisture in semi-arid areas with multi-temporal RADARSAT-2 data}

\begin{abstract}
Soil moisture content is a very important factor in terms of energy exchange and water cycle on Earth and has a great impact in many areas regarding assessment of natural risks, hydrology, ecology, agriculture, and climate science. Soil moisture can greatly change spatially and temporally, especially depending on land use changes, and the changing soil moisture may cause various environmental and ecological problems. In this respect, it is an important research subject to examine the spatial change of soil moisture content on large scales. Synthetic Aperture Radar (SAR) sensors play an important role in detecting soil moisture because they are sensitive to soil moisture and they cover large areas. In this study, it was aimed to investigate the determination of the spatial and temporal variation of soil moisture content using fully polarimetric RADARSAT-2 images in wheat cultivated field and fallow land located in The General Directorate of Agricultural Enterprises Gözlü Agricultural Enterprise. The in-situ measurements obtained monthly from field surveys between March and October 2016 were compared with the backscatter values of SAR images. As a result of the study, negative and positive correlation coefficients varying from -0.65 to 0.67 were obtained between backscatter values and in-situ soil moisture values. The highest correlations for soil moisture were obtained in the cultivated area during the May-June period, which is the growing stage of wheat, and the best results for both areas were determined with VV polarimetric data.
\end{abstract}

Keywords: Soil moisture, Temporal analysis, SAR, RADARSAT-2 


\section{Giriş}

Dünyanın karşı karşıya olduğu en önemli problemlerden biri küresel ısınma ve buna bağlı iklim değişimidir. Küresel ısınmaya bağlı iklim değişikliğinin, kara ve deniz buzullarının erimesi, deniz seviyesinin yükselmesi, iklim kuşaklarının yer değiştirmesi, ani taşkınların ve sellerin daha sık oluşması ve etkilerinin kuvvetlenmesi, kuraklık, çölleşme gibi insan yaşamını, sosyoekonomik sektörleri ve ekolojik sistemleri doğrudan ya da dolaylı olarak etkileyebilecek önemli sonuçlarının olacağ1 öngörülmektedir (IPCC, 2001; Sertel, 2008; Sertel \& Örmeci, 2009).

Kuraklık Türkiye'de en az anlaşılan ve aynı zamanda en çok zarar veren doğal afetlerden biridir. İklimin doğal bir parçasıdır, ancak raslantısal olarak ve seyrek bir şekilde oluştuğu düşünülmektedir. Kuraklık aynı zamanda iklimin su kaynaklarını, tarımı ve tüm canlıları etkileyen bir şeklidir ve yarı kurak bir iklim kuşağında yeralan ülkemizin kuraklığın şiddetini yakın bir gelecekte bugünkünden çok daha fazla hissedebileceği aşikardır. Bu durumun en belirgin göstergesi ise küresel iklim değişimi sonucunda, ülkemizde de yağışların alansal dağılımının, şiddetinin ve süresinin değişiyor olmasıdır (Demir, Kılıç, Coşkun, \& Sümer, 2008). Bunun sonucunda da ülkemizde buharlaşma artmakta, yağış düzeni değişmekte, toprak nemi ve kar örtüsü azalmakta, şiddetli yağışların sıklığı artmakta, akışlar ve akifer beslenmesinde azalmalar olmakta, şehirlerde ani seller ve kıyısal alanlarda deniz suyu girişi artmakta ve barajlarda daha fazla buharlaşmayla kayıplar olmaktadır (Kadığlu, 2008; Kapluhan, 2013; Türkeş, 2007). Kuraklık; normalin altında yağış, düşük toprak nemi, sıcak kuru hava gibi birçok faktörün bileşiminin bir sonucudur. Bunun için sıcaklık, yağış, yüzey akışı, toprak nemi gibi ana iklimsel ve hidrolojik değişkenler düzenli olarak izlenmeli ve normal değerlerden olan sapmaların trendi gözlenmelidir.

Ülkemizde, değişik kuraklık endeksleri hazırlayıp, yeraltı suyu, akarsu ve göllerdeki su miktarını, toprak nemi ve uzun vadeli yağış tahminlerini bir elde toplayıp değerlendirebilen herhangi bir kurum veya kuruluş bulunmamaktadır. Dolayısıyla kuraklığın gelişimini, günlük/aylık olarak takip ederek, kurak ve nemli alanların ve bunların şiddetinin yerel dağılımı hakkında doğru ve zamanında bilgi sahibi olunamamaktadır. Ülkemizde şu ana kadar çeşitli kurum ve kuruluşlarca bazı alanlarda sıcaklık, yağış ve akım ölçümü yapılmış olmasına karşın diğer bir önemli kuraklık parametresi olan toprak nemine ilişkin düzenli ve sürekli bir izleme çalışması bulunmamaktadır (Kadıoğlu, 2008, 2012).

Yüzey toprağının nem içeriği; atmosfer ve toprak yüzeyi arasında enerji transferi ile su dolaşımını etkileyen hidrolojik dinamiklerdeki çok önemli değişkenlerden birini oluşturmaktadır. Toprak neminin konumsal ve zamansal değişiminin doğru tahmini çevre ile ilgili pek çok çalışma açısından önem taşımaktadır. Uydular ile yapılan uzaktan algılama bilimindeki son teknolojik gelişmeler, birçok uzaktan algılama teknolojisi ile (zayıf ve güçlü yönleriyle) toprak neminin ölçülebildiğini göstermektedir (Baghdadi, Aubert, \& Zribi, 2011; Wang \& Qu, 2009; Zribi, Baghdadi, Holah, \& Fafin, 2005). Özellikle yüzey toprak nemi, mikrodalga uzaktan algılama teknolojisi ile uyumlu olan, bir dizi teorik, deneysel veya yarı deneysel model kullanılarak tahmin edilebilmektedir (Baghdadi, vd., 2011; Bousbih vd., 2018; Dubois, van Zyl, \& Engman,, 1995; Huang vd., 2019; Oh, 2004; Şekertekin, Marangoz, \& Abdikan, 2020; Xie vd., 2017; Zribi vd., 2005).

Sentetik Açıklıklı Radar (SAR) algılayıcılara sahip sistemler, yeryüzü gözlemleri için en çok kullanılan mikrodalga uzaktan algılama sistemleridir. Pek çok çalışma X-bant (Baghdadi, Zribi, Loumagne, Ansart, \& Anguela, 2008; Zribi vd., 2011), Cbant (Baghdadi, Gaultier, \& King, 2002; Kurucu, Şanl1, Esetlili, Bolca, \& Göksel, 2009; Moran vd., 2012; Şekertekin, Marangoz, \& Abdikan, 2018) ve L-bant (Şekertekin vd., 2020) gibi farklı dalga boylarına sahip uydu görüntülerini kullanarak yüzey toprak nemini elde etmiştir (Şekertekin vd., 2018).

Baghdadi vd. (2002), çalışmalarında çıplak bir arazi üzerinde ERS ve RADARSAT verileri kullanarak toprak nemi ve yüzey pürüzlülüğünü belirlemeyi amaçlamışlardır. Bu çalışmada, Integral Equation Modeli (IEM) ile oluşturulan simüle edilmiş bir 
veri setine sahip yapay sinir ağları kullanılmıştır. Bu ağlar, 3 radar konfigürasyonunun (VV $23^{\circ}$, $\mathrm{HH} 39^{\circ}$ ve $\mathrm{HH} 47^{\circ}$ ) geri saçılım değerleri ile araziden elde edilmiş geniş bir yüzey pürüzlülüğü ve toprak nemi veri setine uygulanmıştır. İkili ve üçlü radar görüntüsü konfigürasyonuna dayanan yaklaşımlar incelenmiş ve test edilmiştir. Üçlü konfigürasyon biraz daha doğru sonuçlar vermiştir. Toprak nemi ve yüzey pürüzlülüğünün karesel ortalama hataları sırasıyla, yaklaşık \%7.6 ve $0.47 \mathrm{~cm}$ bulunmuştur.

Baghdadi vd. (2008) tarafından yürütülen bir başka çalışmada ise, TerraSAR-X verisinin bitki örtüsü olmayan tarım arazilerinde toprak yüzey parametrelerine duyarlılı̆̆ 1 araştırılmıştır. Bu çalışmada, HH polarizasyonda farklı geliş açılarında $\left(26^{\circ}, 28^{\circ}, 50^{\circ}, 52^{\circ}\right)$ alınmış görüntüler kullanılmıştır ve yüksek geliş açısına sahip görüntülerin $\left(50^{\circ}-52^{\circ}\right)$ yüzey pürüzlülüğüne daha duyarlı olduğu gözlenmiştir. Ayrıca duyarlılığın HH polarizasyona sahip L-bant PALSAR (38 $\left.{ }^{\circ}\right)^{\prime}$ da fazla olduğu da gözlenmiştir. Bununla birlikte VV ve HH polarizasyonlarda alınan C-bant ASAR görüntüsünde $\left(23^{\circ}\right)$ ise VV ve HH polarizasyon sonuçları arasında önemli bir fark olmadığı belirtilmiştir.

Moran vd. (2012) tam polarimetrik (HH+VV+HV+VH) RADARSAT-2 (23ํ $\left.41^{\circ}\right)$ görüntüsü kullanarak buğday, arpa, yulaf, mısır ve soğan gibi bitki örtüsü ile kaplı alanlarda toprak parametrelerini araştırmışlardır. Tüm ürünler için HV polarizasyona sahip görüntüde geri saçılım değerinin daha tutarlı sonuçlar verdiği gözlenmiştir. Işın geliş açısının değişimine bağlı olarak ürün deseninin ve toprak koşullarının en duyarsız olduğu polarizasyon da HV görüntüsüdür. HV görüntüsü dışında da HH polarizasyonun toprak nemi değişiminin belirlenmesinde duyarlı olduğu belirtilmiştir.

Şekertekin vd. (2020) çalışmalarında ALOS-2 ve Sentinel-1 verilerini kullanarak SAR görüntülerinin yüzey toprak nemi ile olan ilişkisini incelemiştir. Çalışma alanında 0-5 cm derinlikte toprak örnekleri alınarak nem değerleri gravimetrik yöntem ile elde edilmiştir. ALOS-2 verisinin dalga boyunun daha uzun olmasından dolayı C-banda göre yüzey pürüzlülüğüne daha az duyarlı olduğu, polarizasyonlar karşılaştırıldığında ise VH ve HH polarizasyonlu görüntülerin daha duyarlı olduğu belirtilmiştir. Sentinel-1 sonuçlarında ise, VH görüntüsünün VV görüntüsüne göre daha duyarlı olduğu sonucuna varılmıştır. Açık alanlar için Dubois (Dubois vd., 1995) ve Oh (Oh, 2004) modelleri kullanılarak nem tahmini çalışması uygulanmıştır. Dubois modeli ile yapılan analizlerde Sentinel-1 sonuçlarının ALOS sonuçlarından daha iyi olduğu sonucu elde edilmişstir. Oh modeli sadece ALOS verisine uygulanabilmektedir, ancak başarılı sonuçlar vermemiştir. Bu nedenle ayrıca toprak nemi, geri saçılım, lokal geliş açısı, pürüzlülük ve dielektrik katsayısı kullanılarak deneysel model geliştirilmiştir. Modelde dielektrik katsayısının olmadığı durumlarda C-bant Sentinel-1 verisi ile en iyi $\mathrm{R}^{2}$ değeri 0.77 olarak elde edilmiştir.

Bu çalışmada, Tarım İşletmeleri Genel Müdürlüğü (TİGEM) Gözlü Tarım İşletmesi’nde seçilen ekili ve ekili olmayan alanlarda mikrodalga uydu görüntüleri ile birçok hidroloji modeli ve verim tahmininde girdi olarak yer alan toprak neminin belirlenebilirliğinin araştırılması amaçlanmıştır. Bu amaçla çok zamanlı ve tam polarimetrik RADARSAT-2 uydu görüntülerinin alım tarihleri ile eş zamanlı olarak arazi ölçümleri yapılmış olup, elde edilen değerler ile uydu görüntülerinin geri saçılım değerleri istatistiksel olarak karşılaştırılmıştır.

\section{2. Çalışma Alanı ve Materyal}

\section{1 Çalışma Alanı}

Çalışma, Konya ili Sarayönü ilçesi sınırları içerisinde yer alan TİGEM Gözlü Tarım İşletmesi’nde seçilen bir buğday ekili ve bir nadas parselinde yürütülmüştür (Şekil 1). Çalışma alanı olarak seçilen Gözlü Tarım İşletmesi, Konya’ya 78 km ve Sarayönü’ne 28 km uzaklıkta bulunmaktadır. İşletme, 1940 yılında, Gözlü Gurup Amirliği Ziraat Kombinası adı altında Açık Tarım İşletmesi olarak kurulmuştur. 1950 yılında Devlet Üretme Çiftliği olan işletme, 1984 yılından bu yana TİGEM 
bünyesinde faaliyetlerini sürdürmektedir. İşletmede 20 yıllık ekim üzerine düşen yağış ortalaması 326.1 mm'dir. İşletmenin bulunduğu bölgede kış mevsimi soğuk ve yağışlı, yazlar ise sıcak ve kurak geçmektedir.

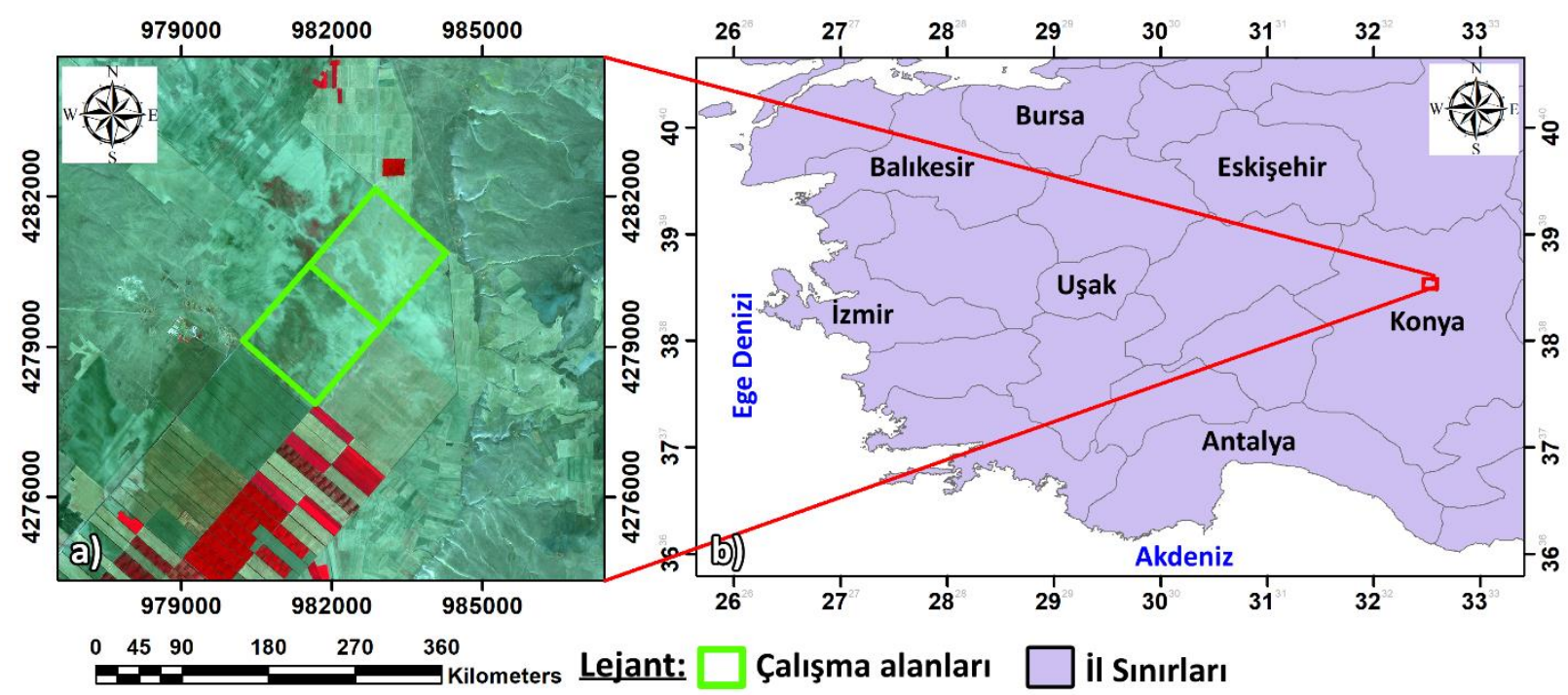

Şekil 1: Çalışma alanının gösterimi: a) Çalışma alanlarının 31 Temmuz 2016 tarihli Sentinel-2 uydu görüntüsü üzerinde Yakın Kızılötesi-Kırmızı-Yeşil band kombinasyonunda gösterimi, b) Çalışma alanının il sınırları içinde gösterimi.

Karasal iklim özelliklerini taşıyan bölgede yağışlar genellikle kış ve ilkbahar aylarında alınmaktadır. Her yıl mart ve nisan aylarında esen rüzgar hızı saatte bazen 100-120 km'ye ulaşmakta ve bölgede rüzgar erozyonu sorunu bulunmaktadır. Bu yüzden işletmede $225 \mathrm{~km}$ orman şeridi tesis edilmiştir. Bu araştırmanın çalışma planına göre, yapılan arazi çalışmaları ile toprak nemi ölçümleri 2016 yılında gerçekleştirilmiştir. Yersel toprak nemi ölçümleri $2 \mathrm{~km}$ x $2 \mathrm{~km}$ boyutlarına sahip olan buğday ekili ve nadas parsellerinde 110'ar noktada $200 \mathrm{~m}$ ara ile grid sisteminde gerçekleştirilmiştir. Çalışma alanında deneme yılında ekili parselde kuru buğday tarımı yapılmıştır. Şekil 2'de çalışma alanlarının arazi çalışmasında çekilmiş görüntüleri verilmektedir.

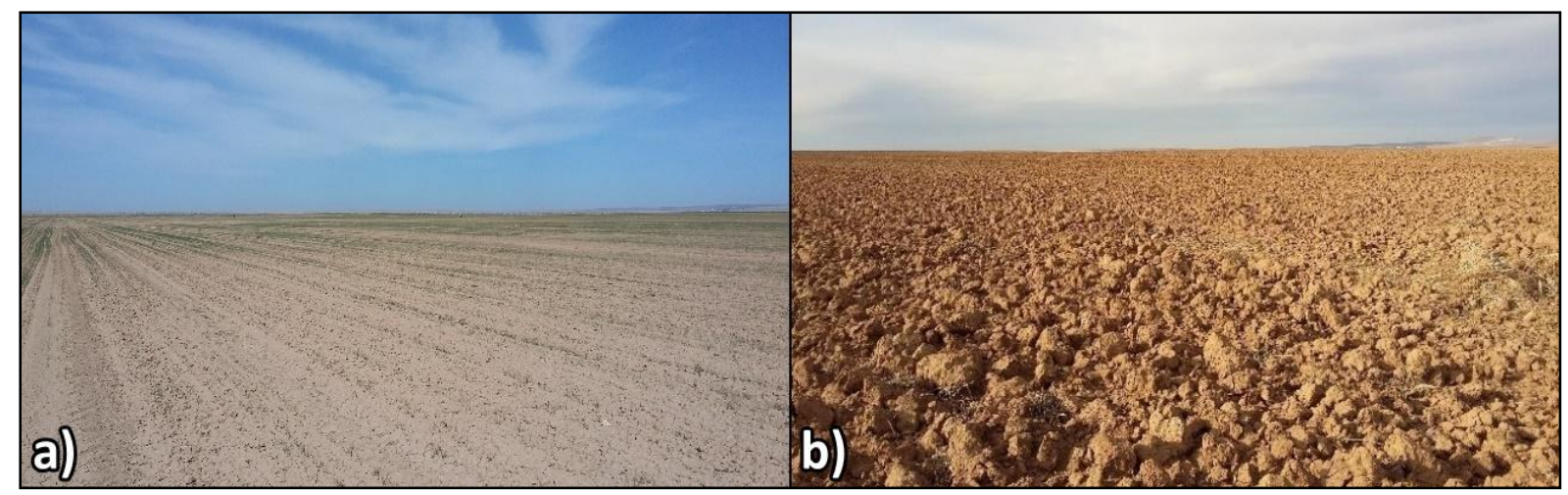

Şekil 2: Çalışma alanları a) Buğday ekili parsel, b) Nadas parseli

\subsection{SAR Uydu Görüntüsünün Özellikleri}

Gerçekleştirilen arazi çalışmaları ile eş zamanlı olarak çalışma alanının RADARSAT-2 uydu görüntüleri alınmıştır. C-banda sahip RADARSAT-2 uydusuna ait görüntüler tek bakışlı karmaşık (Single Look Complex, SLC) görüntü formatında ve tam polarimetrik alım modunda temin edilmiştir. Uyduya ait genel özellikler ve çalışmada kullanılan veri tarihleri Tablo 1'de verilmişsir. 
Tablo 1: RADARSAT-2 uydusunun görüntü özellikleri ve yersel ölçüm ile eş zamanlı alınan uydu görüntülerinin tarihleri

\begin{tabular}{cc}
\hline Yörünge Yönü & Alçalan \\
\hline Alım Modu & FQ21 \\
\hline Frekans & C-band (5.4 GHz) \\
\hline Polarizasyon & HH+HV+VH+VV \\
\hline Çözünürlük & $4.7 \mathrm{~m} \mathrm{x} \mathrm{5.1} \mathrm{m} \mathrm{(Menzil} \mathrm{x} \mathrm{Azimut)}$ \\
\hline Geliş Açısı & $40^{\circ}$ \\
\hline & $09 / 03 / 2016$ \\
\cline { 2 - 2 } & $24 / 04 / 2016$ \\
\cline { 2 - 2 } Veri Alma Tarihleri & $20 / 05 / 2016$ \\
\cline { 2 - 2 } & $14 / 06 / 2016$ \\
\cline { 2 - 2 } & $01 / 07 / 2016$ \\
& $31 / 07 / 2016$ \\
\hline
\end{tabular}

\section{Yöntem}

\subsection{Nem Ölçümü}

Çalışma kapsamda 9 Mart, 24 Nisan, 20 Mayıs, 13 Haziran, 7 Temmuz, 31 Temmuz, 24 Ağustos ve 11 Ekim 2016 tarihlerinde daha önce belirlenen düz ve düze yakın eğimli buğday ekili ve nadas parsellerinde (Şekil 2) toprak nemi ölçümleri gerçekleştirilmiştir. Çalışmada, C-bandının penetrasyon kabiliyetinin yüzeyden $5 \mathrm{~cm}$ derinliğe kadar olması nedeniyle toprak nemi ölçümleri tüm çalışma tarihlerinde gravimetrik olarak 0-5 cm derinlikte yapılmıştır (Xie vd., 2017). Alınan yaş (nemli) toprak örnekleri tartılmış ve daha sonra 24 saat fırında kurutulmuştur. Kuruma işleminin ardından örnekler kuru ağırlığı elde etmek için yeniden tartılmış ve eşitlik (1) kullanılarak toprak nemi değerleri elde edilmiştir. Eşitlikte $N_{1}$ dara ile nemli toprağın ağırlığını, $N_{2}$ dara ile kuru toprağın ağırlığını ve $N_{0}$ dara ağırlığını temsil etmektedir.

$\mathrm{N}=\left(\frac{\left(N_{1}-N_{0}\right)-\left(N_{2}-N_{0}\right)}{\left(N_{2}-N_{0}\right)}\right) \times 100$

\subsection{SAR Verilerinin İşlenmesi}

Öncelikle geri saçılım değerinin elde edilebilmesi için SAR verilerine ön işlem adımları uygulanmıştır. Bu işlemler Avrupa Uzay Ajansı'nın kullanıcılara ücretsiz olarak sunduğu Sentinel Application Platform (SNAP) yazılımı ile gerçekleştirilmiştir. Birinci adım olarak SLC formatında alınmış görüntüler radyometrik kalibrasyon ile doğrusal geri saçılım (sigma nought) değerlerine dönüştürülmüştür (RADARSAT, 2000). Daha sonra 30 m geometrik çözünürlüğe sahip SRTM (Shuttle Radar Topography Mission) sayısal yükseklik modeli kullanılarak topoğrafya düzeltmesi yapılmış ve görüntünün konumsal çözünürlüğü 10 m’ye yeniden örneklenmiştir. Son adımda ise doğrusal olan geri saçılım değerleri desibel (dB) değerine dönüştürülmüştür. Dönüşüm için aşağıdaki (2) ve (3) eşitlikleri kullanılmıştır.

Radar parlaklığı $\left(\beta_{j}^{\circ}\right)$ ve radar geri saçılım katsayısı $\left(\sigma_{j}^{\circ}\right)$ arasındaki ilişki;

$\sigma_{j}^{\circ}=\beta_{j}^{\circ}+10 \log _{10} \sin \mathrm{I}_{\mathrm{j}}$

ile ifade edilir. Burada $\mathrm{I}_{\mathrm{j}}$, j. pikseldeki geliş açısıdır. $\beta_{j}^{\circ}$, j. pikseldeki radar parlaklık değeri; 
$\beta_{j}^{\circ}=20 \log _{10}\left(D N_{j} / A_{j}\right)$

ile ifade edilir.

\section{Değerlendirme ve Tartışma}

Nadas parselinde ve buğday ekili parselde 9 Mart 2016 ile 11 Ekim 2016 tarihleri arasında yapılan arazi çalışmalarında belirlenen ortalama nem içeriği ve her bir tarihteki geri saçılım değerlerine ait değişim Şekil 3'te verilmiştir. En yüksek nem içeriği her iki parselde de 20 Mayıs 2016 tarihli ölçümde belirlenmiştir ve genel olarak toprak nem içeriği her iki alanda da benzer eğilim göstermiştir. Arazi ölçümlerinden elde edilen nem verileri ile eş zamanlı alınan RADARSAT-2 görüntülerine ait geri saçılım değerleri arasında doğrusal regresyon analizi yapılarak Pearson Korelasyon Katsayıları (Pearson Correlation Coefficient, PCC) elde edilmiş ve her polarizasyon verisi için incelenmiştir (Şekil 4). En yüksek nem değerleri 20 Mayıs 2016 tarihinde nadas parselinde ortalama \%14.49, buğday ekili parselde ortalama \%15.37, en düşük değerler ise 24 Ağustos 2016 tarihinde nadas parselinde ortalama \%5.75, buğday parselinde ise ortalama \%6.31 olarak belirlenmiştir. Her bir alan için dört farklı polarizasyonda değerlendirme yapılmış ve en yüksek PCC değerini veren polarizasyondaki değer verilmiştir. Buna göre doğrudan geri saçılım ile nem değerleri arasında -0.65 ile 0.67 arasında değişen negatif ve pozitif korelasyon katsayıları elde edilmiştir. En yüksek negatif PCC değeri 14 Haziran 2016 tarihinde ekili alanda VH'de -0.65 olarak belirlenirken, en yüksek pozitif değer ise 20 Mayıs 2016 tarihinde ekili alanda VV'de 0.67 olarak belirlenmiştir. Nadasa bırakılan alanda ise değerler -0.62 (Nisan) ve 0.64 (Ekim) değerleri arasında değişmektedir. Her dört polarizasyonda da ekili alanda Haziran ayından itibaren korelasyon değerlerinde düşüş olduğu görülmektedir. Bitkinin gelişimi ile birlikte uydudan elde edilen geri saçılım değeri, bitki ve topraktan alınan geri saçılımların toplamına eşittir. Bu nedenle, burada bitkinin geri saçılımdaki etkisi görülmektedir. Nadasa bırakılan alanda da üçleme işleminin yapıldığı Haziran ayından itibaren PCC değerlerinde artış görülmektedir (Şekil 4).

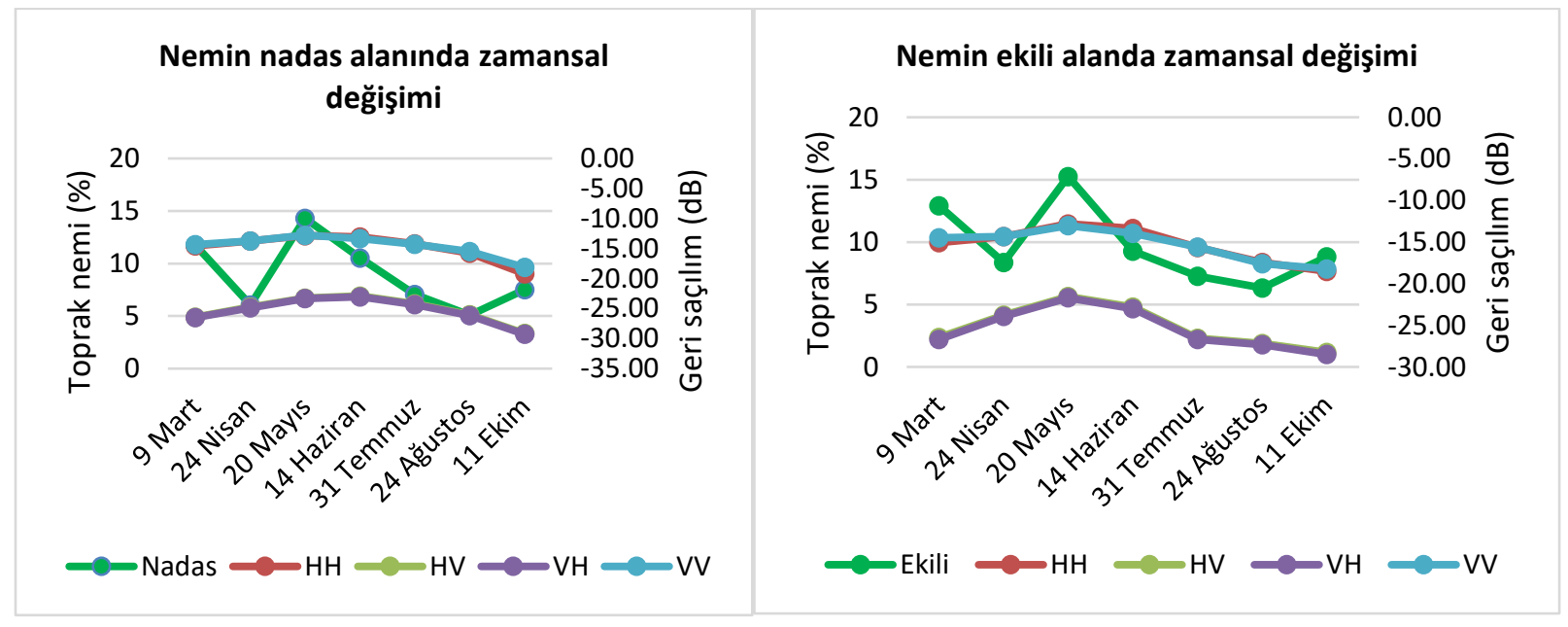

Şekil 3: Nemin nadas ve ekili alanda zamansal değişimi

Bu konuda daha önce yapılan çalışmaların sonuçları, çalışmanın yürütüldüğü koşullar ve kullanılan metodolojilere bağlı olarak geniş bir aralıkta korelasyon değerleri elde edilebileceğini göstermiştir (Baghdadi vd., 2002; Chai vd., 2015; Chen vd., 2012; Kaleita, Tian, \& Hirschi, 2005; Lievens \& Verhoens, 2012; Rahman vd., 2008; Yang, Feng, Liu F., Liu J., \& Sun, 2019; Y1lmaz, 2008). Yang vd. (2019) RADARSAT-2 verilerini kullanarak çıplak arazide 0-5 cm derinlikten alınan ve gravimetrik ölçümle elde edilen nem değerlerini karşılaştırmıştır. Çalışmada lineer geri saçılım değerleri yerine polarimetrik ürünler kullanılmıştır. Polarimetrik parametreler arttıkça lineer korelasyon sonucu elde edilen korelasyon sonuçlarının da 
arttığı görülmüştür. Tek bir polarimetrik parametrenin korelasyon değeri 0.43 iken çoklu parametre ile bu değerin 0.68 'e çıktığı belirlenmiştir. Ancak tek tarihli bir görüntünün tüm polarimetrik verileri incelendiğinde korelasyon katsayılarının çok daha düşük olduğu ve en iyi polarimetrinin VH $(\mathrm{R}=0.19)$ ile elde edildiği belirlenmiştir. Bu çalışmada ise farklı tarihlerde alınan görüntüler ile korelasyonun değiş̧iği belirlenmiştir (Şekil 4).

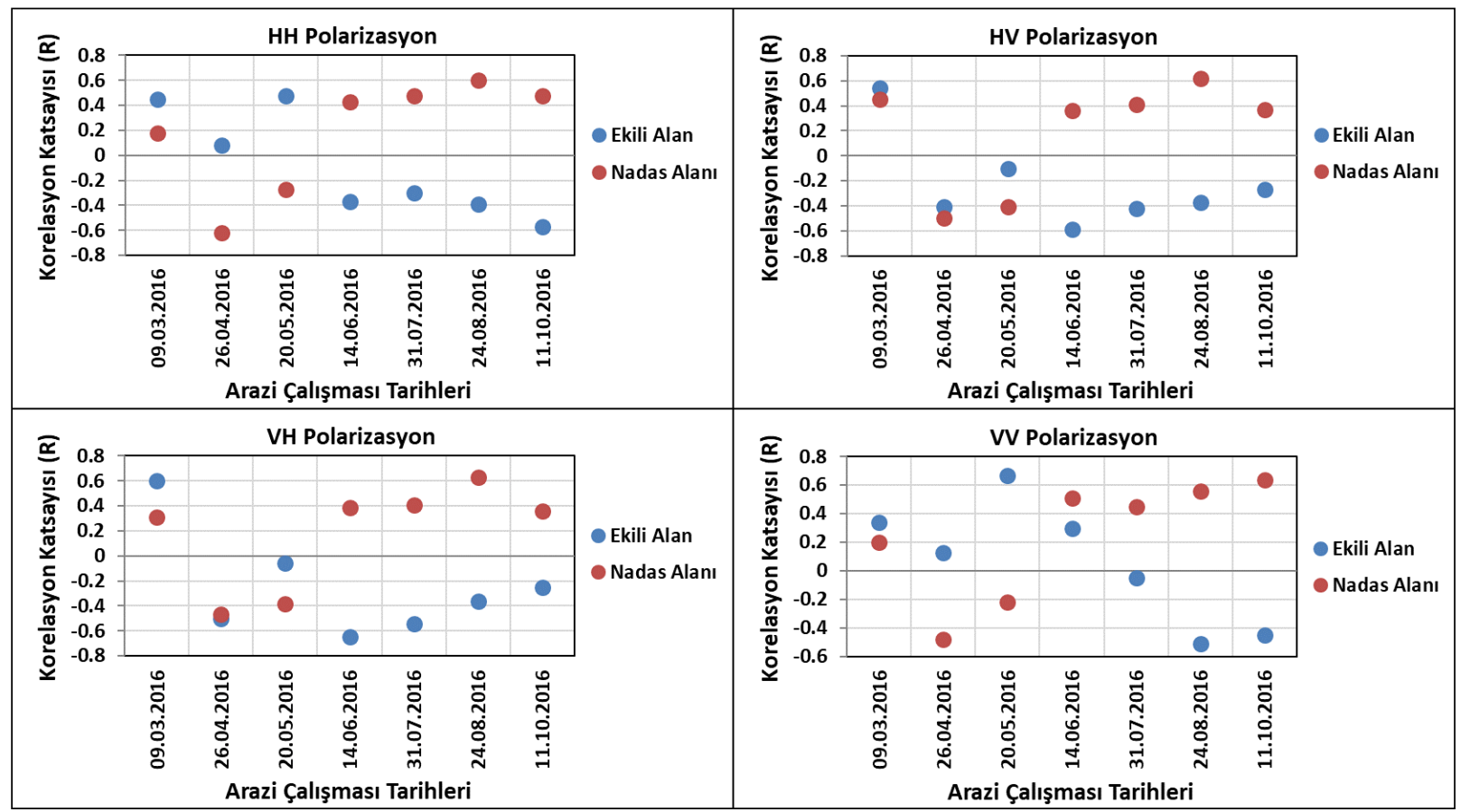

Şekil 4: Nem değerleri ile RADARSAT-2 görüntüleri arasındaki korelasyon değerleri

Ezzahar vd. (2020) C-bant Sentinel-1 verisi ile yaptıkları çalışmada üzerinde bitki olmayan boş arazide $5 \mathrm{~cm}$ derinlikten elde ettikleri nem değerlerini kullanmışlardır. Toprak nemi ve geri saçılım değerlerine ait regresyon değerleri incelendiğinde VV polarizasyona sahip görüntünün toprak neminin belirlenmesinde $\mathrm{VH}$ polarizasyona göre daha uygun olduğu belirtilmiştir. Benzer şekilde bu çalışmada da C-bant VV polarizasyona sahip görüntünün nadas parselinde en yüksek sonucu verdiğgi bulunmuştur. Holah, Baghdadi, Zribi, Bruand ve King (2005) toprak nemi ile çok zamanlı ve farklı geliş açısına sahip C-bant Envisat verisi arasındaki ilişkiyi incelemiş ve en iyi sonucun $34^{\circ}-37^{\circ}$ geliş açısına sahip HV verisi $\left(\mathrm{R}^{2}=0.68\right)$ ile elde edildiğini belirtmiştir. Ancak korelasyonun $40^{\circ}-43^{\circ}$ geliş açısına sahip veriler ile incelendiğinde hem $H V\left(R^{2}=0.33\right)$ hem de $\mathrm{HH}\left(\mathrm{R}^{2}=0.21\right)$ verileri için daha düşük olduğu sonucuna varılmıştır. Bu çalışmada ise $40^{\circ}$ geliş açısına sahip $\mathrm{C}$-bant RADARSAT-2 verileriyle daha yüksek ilişki kurulduğu tespit edilmiştir.

Chai vd. (2015) çayır alanında toprak neminin belirlenmesinde RADARSAT-2 verilerini kullanmışlardır. Çalışmada Dubois ve Chen modelleri kullanılmış ve toprak nemi kestirimi yapılmıştır. Uygulamada 2 görüntü kullanılmış ve bu görüntü alımları sırasında sırasıyla 33 ve 32 test alanı belirlenmiştir. Her test alanı için 100x100 m alanda 3 alım gerçekleştirilmiştir. Sadece iki polarimetri verisi olan $\mathrm{HH}$ ve VV görüntüleri kullanılarak elde edilen modellerden test alanları için en iyi $\mathrm{R}^{2}$ değerleri sırasıyla 0.8 (Dubois) ve 0.75 (Chen) bulunmuştur. Çalışmada polarimetrik veriler ayrı ayrı incelenmemiş olup verilerin beraber ele alındığı modeller ele alınmıştır. Bu çalışmada ise tüm polarimetreler ayrı ayrı ele alınmış ve tek bir polarimetrik görüntü ile 0.65 'in üzerinde korelasyon sağlanabileceği belirlenmiştir. Çalışma sonucunda, ekili alanda en yüksek korelasyonu 20 Mayıs 2016 tarihli VV polarimetrede elde edilmiş veri sağlarken, nadasa bırakılmış alanda 11 Ekim 2016 tarihli VV verisi sağlamıştır. Bu iki veri için Kriging yöntemi ile nem haritaları oluşturulmuş ve yersel ölçümlerden elde edilen değerlerden çıkarılarak alansal olarak hata değerleri elde edilmiştir (Şekil 5). 


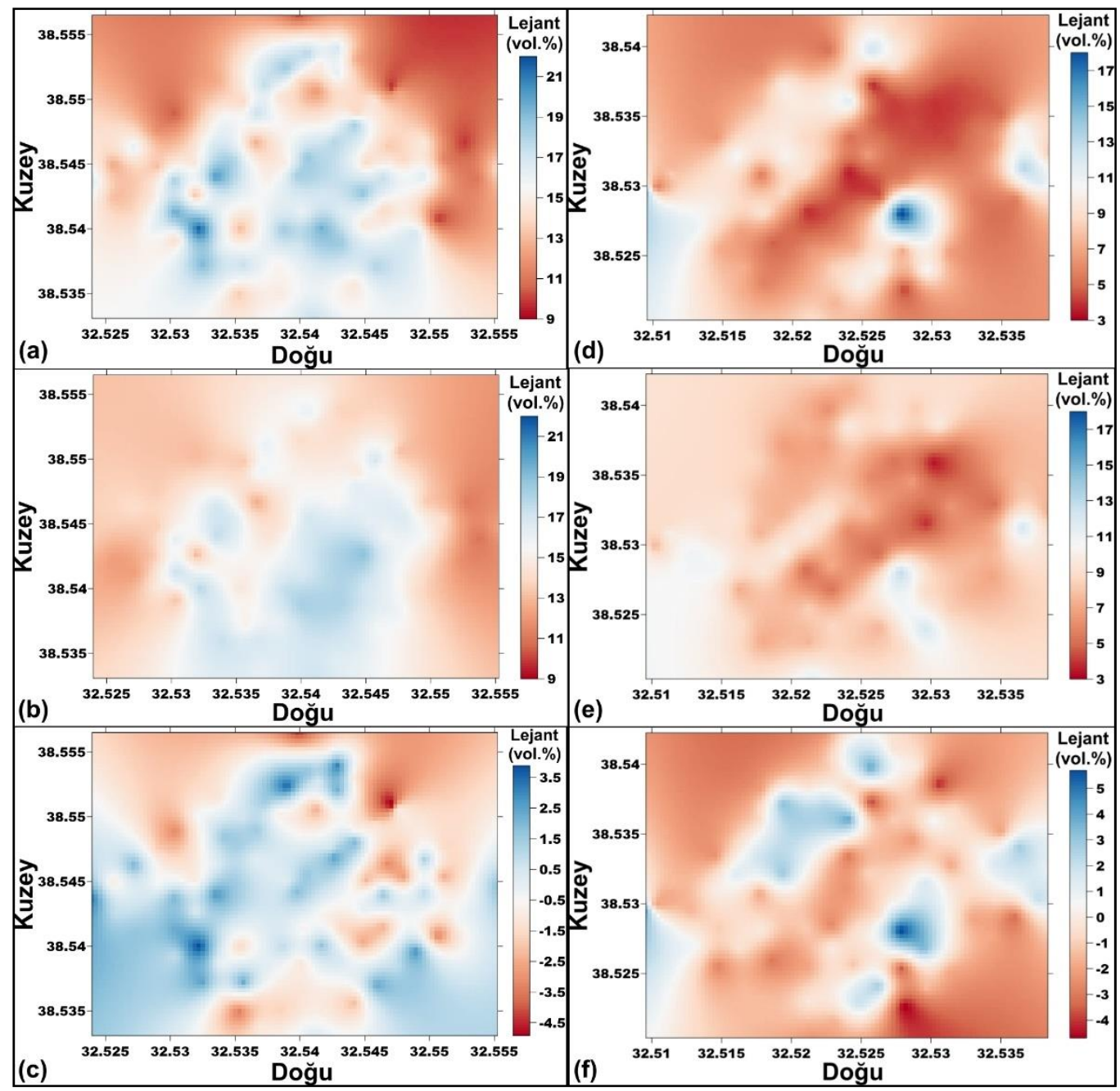

Şekil 5: 20 Mayıs 2016 ekili alan için sırasıyla a) Yersel nem ölçümü, b) Tahmin edilen nem, c) Yersel ve tahmin edilen nem farkı. 11 Ekim 2016 tarihli nadas alan için sırasıyla d) Yersel nem ölçümü, e) Tahmin edilen nem, f) Yersel ve tahmin edilen nem farkı

\section{Sonuç ve Öneriler}

Bu çalışmada, Konya ili sınırları içerisinde yer alan TİGEM Gözlü Tarım İşletmesi içerisinde yer alan buğday ekili ve nadas parsellerinde 9 Mart 2016 ile 11 Ekim 2016 tarihleri arasında yaklaşık birer aylık aralıklar ile toprak neminin zamansal değişimi RADARSAT-2 SAR uydu görüntüleri ile belirlenmiştir. Hangi polarimetrik verinin daha iyi sonuç verdiğini belirlemek için dört polarimetrik (HH, HV, VH ve VV) veriye ait geri saçılım değerleri ile yersel veriler arasındaki korelasyon değerleri karşılaştırılmıştır. Toprak neminin en iyi belirlenebildiği dönemi belirlemek amacıyla zamansal bir analiz gerçekleştirilmiştir.

Toprak nemi incelendiğinde ekili alan için buğdayın büyüme evresi olan mayıs-haziran döneminde daha yüksek korelasyon sağlandığı görülmüştür, en iyi sonuç VV polarimetrik verisi ile tespit edilmiştir. Benzer şekilde nadasa bırakılan alanda da en iyi sonuç VV polarimetrik verisi ile elde edilmiştir. VV polarimetrik verisine alternatif olarak ikinci sırada VH verisi yüksek değerler vermiştir.

SAR görüntüleriyle yapılan nem çalışmalarında sonucu etkileyen pek çok sistem parametresi ile birlikte hedef nesneye ait parametreler de yer almaktadır. Sonraki çalışmalarda polarimetrik verinin geri saçılım değerleri ile birlikte geri saçılım matris (SAR decomposition) bilgilerinin de kullanılarak farklı modellerle uygulanması düşünülmektedir. Bitkili alanlarda da bitkiye 
ait yükseklik ve yüzey kaplama gibi parametrelerin de ele alındı̆̆ı modellerin geliştirilmesi planlanmaktadır. Ayrıca, optik ve mikrodalga görüntülerin birlikte kullanımı ile elde edilecek doğrulukların artacağı düşünülmektedir.

\section{Teşekkür}

Çalışmada Tarım ve Orman Bakanlığı Tarımsal Araştırmalar ve Politikalar Genel Müdürlüğü tarafından desteklenen TAGEM/TSKAD/14/A13/P05/03 nolu proje kapsamında elde edilen veriler kullanılmıştır. TAGEM'e ve proje ekibine katkılarından dolayı teşekkür ederiz.

\section{Yazar Katkısı}

Sevinç Madenoğlu: Fikir, Tasarım, Literatür taraması, Veri toplama ve işleme, Analiz ve yorumlama, Denetleme, Finansman, Yazım. Hesna Özcan: Veri toplama ve işleme, Analiz ve yorumlama. Murat Remzi Peker: Veri toplama ve işleme, Analiz ve yorumlama. Melis Özge Pınar: Tasarım, Veri toplama ve işleme, Analiz ve yorumlama, Yazım. Suat Akgül: Tasarım, Denetleme, Finansman. Mehmet Keçeci: Veri toplama. Tülay Tunçay: Veri toplama. Mahmut Hilmi Seçmen: Veri toplama, Analiz. Ali Koç: Tasarım, Veri toplama. Mustafa Üstüner: Literatür taraması, Veri toplama ve işleme, Analiz ve yorumlama, Yazım. Aliihsan Şekertekin: Literatür taraması, Veri toplama ve işleme, Analiz ve yorumlama, Yazım. Saygın Abdikan: Fikir, Tasarım, Literatür taraması, Veri toplama ve işleme, Analiz ve yorumlama, Yazım. Mustafa Tolga Esetlili: Fikir, Tasarım, Literatür taraması, Veri toplama ve işleme. Aynur Şensoy Şorman: Fikir, Tasarım. Şinasi Kaya: Fikir, Tasarım. Günay Erpul: Fikir, Tasarım. Füsun Balık Şanlı: Fikir, Tasarım, Literatür taraması, Veri toplama ve işleme, Analiz ve yorumlama, Denetleme, Yazım.

\section{Çıkar Çatışması Beyanı}

Yazarlar, bu çalışmada bilinen ilgili herhangi bir finansal veya finansal olmayan çıkar çatışması olmadığını beyan eder.

\section{Kaynaklar}

Baghdadi, N., Gaultier, S., \& King, C. (2002). Retrieving surface roughness and soil moisture from synthetic aperture radar (SAR) data using neural networks. Canadian Journal of Remote Sensing, 28(5), 701-711.

Baghdadi, N., Zribi, M., Loumagne, C., Ansart, P., \& Anguela, T. P. (2008). Analysis of TerraSAR-X data and their sensitivity to soil surface parameters over bare agricultural fields. Remote sensing of environment, 112(12), 4370-4379.

Baghdadi, N., Aubert, M., \& Zribi, M. (2011). Use of TerraSAR-X data to retrieve soil moisture over bare soil agricultural fields. IEEE Geoscience and Remote Sensing Letters, 9(3), 512-516.

Bousbih, S., Zribi, M., El Hajj, M., Baghdadi, N., Lili-Chabaane, Z., Gao, Q., \& Fanise, P. (2018). Soil moisture and irrigation mapping in A semi-arid region, based on the synergetic use of Sentinel-1 and Sentinel-2 data. Remote Sensing, 10(12), 1953.

Chai, X., Zhang, T., Shao, Y., Gong, H., Liu, L., \& Xie, K. (2015). Modeling and mapping soil moisture of plateau pasture using RADARSAT-2 imagery. Remote Sensing, 7(2), 1279-1299.

Chen, X. Z., Chen, S. S., Zhong, R. F., Su, Y. X., Liao, J. S., Li, D., Han, L. S., \& Li, X. (2012). A semi-empirical inversion model for assessing surface soil moisture using AMSR-E brightness temperatures. Journal of Hydrology, 456, 1-11.

Demir, İ., Kılıç, G., Coşkun, M., \& Sümer, U. M. (2008). Türkiye'de maksimum, minimum ve ortalama hava sıcaklıkları ile yağış dizilerinde gözlenen değişiklikler ve eğilimler. TMMOB İklim Değişimi Sempozyumu, Bildiriler Kitabı, 69-84.

Dubois, P. C., van Zyl, J., \& Engman, T. (1995). Measuring soil moisture with imaging radars. IEEE transactions on geoscience and remote sensing, 33(4), 915-926. 
Ezzahar, J., Ouaadi, N., Zribi, M., Elfarkh, J., Aouade, G., Khabba, S., Er-Raki, S., Chenbouni, A., \& Jarlan, L. (2020). Evaluation of backscattering models and support vector machine for the retrieval of bare soil moisture from Sentinel-1 data. Remote Sensing, 12(1), 72.

Holah, N., Baghdadi, N., Zribi, M., Bruand, A., \& King, C. (2005). Potential of ASAR/ENVISAT for the characterization of soil surface parameters over bare agricultural fields. Remote sensing of environment, 96(1), 78-86.

Huang, S., Ding, J., Zou, J., Liu, B., Zhang, J., \& Chen, W. (2019). Soil moisture retrival based on sentinel-1 imagery under sparse vegetation coverage. Sensors, 19(3), 589.

IPCC (2001). Climate Change 2001: The Scientific Basis. Contribution of Working Group I to the Third Assessment Report of the Intergovernmental Panel on Climate Change, The Press Syndicate of the University of Cambridge.

Kadığlu, M. (2008). Kuraklık Kıranı Risk Yönetimi. Kadığlu, M., \& Özdamar, E. (ed) Afet Zararlarını Azaltmanın Temel İlkeleri (s. $277-$ 300). Ankara: JICA Türkiye Ofisi Yayınları No: 2.

Kadığlu, M. (2012). Türkiye'de İklim Değişikliği Risk Yönetimi. Türkiye’nin İklim Değişikliği II. Ulusal Bildiriminin Hazırlanması Projesi Yayın1.

Kaleita, A. L., Tian, L. F., \& Hirschi, M. C. (2005). Relationship between soil moisture content and soil surface reflectance. Transactions of the ASAE, 48(5), 1979-1986.

Kapluhan, E. (2013). Türkiye'de Kuraklık ve Kuraklığın Tarıma Etkisi. Marmara Coğrafya Dergisi, 27, 487-510.

Kurucu, Y., Şanlı, F. B., Esetlili, M. T., Bolca, M., \& Göksel, C. (2009). Contribution of SAR images to determination of surface moisture on the Menemen Plain, Turkey. International Journal of Remote Sensing, 30(7), 1805-1817.

Lievens, H., \& Verhoest, N. E. (2012). Spatial and temporal soil moisture estimation from RADARSAT-2 imagery over Flevoland, The Netherlands. Journal of Hydrology, 456, 44-56.

Moran, M. S., Alonso, L., Moreno, J. F., Mateo, M. P. C., De La Cruz, D. F., \& Montoro, A. (2012). A RADARSAT-2 quad-polarized time series for monitoring crop and soil conditions in Barrax, Spain. IEEE Transactions on Geoscience and Remote Sensing, 50(4), 1057-1070.

Oh, Y. (2004). Quantitative retrieval of soil moisture content and surface roughness from multipolarized radar observations of bare soil surfaces. IEEE Transactions on Geoscience and Remote Sensing, 42(3), 596-601.

RADARSAT (2000). Data Product Specification, RSI-GS-026, Revizyon 3,1-125.

Rahman, M. M., Moran, M. S., Thoma, D. P., Bryant, R., Collins, C. H., Jackson, T., Orr, B. J., \& Tischler, M. (2008). Mapping surface roughness and soil moisture using multi-angle radar imagery without ancillary data. Remote Sensing of Environment, 112(2), 391-402.

Sertel, E. (2008). Remote Sensing and Regional Climate Modeling of the Impacts of Land Cover Changes on the Climate of the Marmara Region of Turkey (Doktora Tezi), İstanbul Teknik Üniversitesi, Fen Bilimleri Enstitüsü, İstanbul, Türkiye.

Sertel E., \& Örmeci, C. (2009). Uzaktan Algılama Verilerinin İklim Biliminde Kullanım Olanakları. 12. Türkiye Harita Bilimsel ve Teknik Kurultayı, Ankara

Şekertekin, A., Marangoz, A. M., \& Abdikan, S. (2018). Soil moisture mapping using Sentinel-1A synthetic aperture radar data. International Journal of Environment and Geoinformatics, 5(2), 178-188.

Şekertekin, A., Marangoz, A. M., \& Abdikan, S. (2020). ALOS-2 and Sentinel-1 SAR data sensitivity analysis to surface soil moisture over bare and vegetated agricultural fields. Computers and Electronics in Agriculture, 171, 105303.

Türkeş, M. (2007). İnsanın küresel iklim üzerindeki etkileri, gözlenen ve öngörülen iklim değişkenliği ve değişiklikleri ile sonuçları. Küresel İklim Değişimi ve Su Sorunlarının Çözümünde Ormanlar Sempozyumu, İstanbul.

Wang, L., \& Qu, J. J. (2009). Satellite remote sensing applications for surface soil moisture monitoring: A review. Frontiers of Earth Science in China, 3(2), 237-247.

Xie, Q., Meng, Q., Zhang, L., Wang, C., Sun, Y., \& Sun, Z. (2017). A soil moisture retrieval method based on typical polarization decomposition techniques for a maize field from full-polarization radarsat-2 data. Remote Sensing, 9(2), 168.

Yang, L., Feng, X., Liu, F., Liu, J., \& Sun, X. (2019). Potential of soil moisture estimation using C-band polarimetric SAR data in arid regions. International Journal of Remote Sensing, 40(5-6), 2138-2150.

Yılmaz, M. (2008). Active Microwave Remote Sensing of Soil Moisture: A Case Study in Kurukavak Basin (Doktora Tezi). Orta Doğu Teknik Üniversitesi, Fen Bilimleri Enstitüsü, Ankara, Türkiye.

Zribi, M., Baghdadi, N., Holah, N., \& Fafin, O. (2005). New methodology for soil surface moisture estimation and its application to 
ENVISAT-ASAR multi-incidence data inversion. Remote sensing of environment, 96(3-4), 485-496.

Zribi, M., Kotti, F., Lili-Chabaane, Z., Baghdadi, N., Issa, N. B., Amri, R., Duchemin, B., \& Chehbouni, A. (2011). Soil texture estimation over a semiarid area using TerraSAR-X radar data. IEEE Geoscience and Remote Sensing Letters, 9(3), 353-357.

\section{Yazar Bilgileri}

\section{iD}

\section{$\triangle$}

0000-0002-5012-2773, sevinc.madenoglu@ tarimorman.gov.tr (Madenoğlu S.)*

0000-0003-2546-500X, hesna.ozcan@tarimorman.gov.tr (Özcan H.)

0000-0002-6596-8982, murat.peker@tarimorman.gov.tr (Peker M.R.)

0000-0002-4348-5541, melisozge.pinar@tarimorman.gov.tr (Pınar M.Ö.)

0000-0001-7122-2151, suat.akgul@tarimorman.gov.tr (Akgül S.)

0000-0003-1665-4677, mehmet.kececi@tarimorman.gov.tr (Keçeci M.)

0000-0001-5398-5497, tulay.tuncay@tarimorman.gov.tr (Tunçay T.)

0000-0002-5151-5907, mahmuthilmi.secmen@tarimorman.gov.tr (Seçmen M.H.)

0000-0002-8744-5939, alikoc6164@hotmail.com (Koç A.)

0000-0003-0553-2682, mustuner@artvin.edu.tr (Üstüner M.)

0000-0002-4715-5160, asekertekin@cu.edu.tr (Şekertekin A.)

0000-0002-3310-352X, sayginabdikan@ hacettepe.edu.tr (Abdikan S.)

0000-0002-8095-4247, tolga.esetlili@ege.edu.tr (Esetlili M.T.)

0000-0003-3004-4912, asensoy@eskisehir.edu.tr (Sensoy A.)

0000-0002-4962-0492, kayasina@itu.edu.tr (Kaya Ş.)

0000-0002-3797-6969, erpul@ankara.edu.tr (Erpul G.)

0000-0003-1243-8299, fbalik@yildiz.edu.tr (Balık Şanlı F.) 